\title{
Exploring and Experimenting Cooperative Design
}

\author{
Salomão David ${ }^{(\bowtie)}$ and Lorenzo Cantoni \\ Faculty of Communication Sciences, Universita della Svizzera Italiana, \\ via G. Buffi. 13, 6900 Lugano, Switzerland \\ \{salomao.david.cumbula, lorenzo.cantoni\}@usi.ch
}

\begin{abstract}
This paper describes a community co-design approach performed in rural Mozambique. It discusses the experiences and experiments performed in a community multimedia center towards creating services with inherent values for daily community activities. The design approach pursues a holistic interpretation of community needs, and discusses emerging, new and creative applications for future community binding.
\end{abstract}

Keywords: Community design · Co-design · ICT4D · Development · Tourism · And education

\section{Introduction}

The sub-Saharan Africa faces development problems, reflected in high unemployment, digital divide, disparities in access to health, and education [1]. To tackle these issues donors and sub-Saharan nations devoted significant human and financial resources to Information and Communication Technologies (ICTs), creating public access venues or ICT venues. Public access venues are locations that provide access to computer and Internet services, open to the public. They are also defined as a place that offers public access to information with services available to everyone, and not directed to one group excluding others [2]. Examples of public access venues established in sub-Saharan Africa are telecentres, community radios, cybercafés, millennium villages, and libraries.

The birth of public access venues was expected to improve efficiency in government service delivery, and to contribute to development, to promote digital inclusion through technology, information access and development of ICT skills [3]. Public access venues have high social impact on users, deliver benefits that touch aspects of users livelihood, including access to culture, education, communication, information, political participation, and leisure.

This paper presents a collaborative approach used to design a solution with inherent value for the community of Morrumbene, in Mozambique. The case shows how involving individuals, social groups, and organizations, can provide conditions to create an environment to produce a social and financial sustainable solution.

The rest of the paper is organized as follows: in the next three sections, we present an overview on public access venues in Mozambique, their context, and the methodological framework used in this action-research. The last two sections present the outcome 
of the intervention, and provide a discussion, which includes stakeholders, context, ownership, and sustainability.

\section{Public Access Venues in Mozambique}

Mozambique is a country located in sub-Saharan Africa, bordered by the Indian Ocean on the east, Zimbabwe on the west, Tanzania and Malawi on the north, and South Africa on the south. The country has approximately $70 \%$ of inhabitants living in rural areas [4].

In 1999, Mozambique witnessed the establishment of two public access venues in Manhiça and Namaacha districts. These venues were conceived to provide access to computers, ICT training (word, excel, power point, graphic design), public phone, fax, photocopy and Internet [5].

Communities' information, technology, and leisure needs were somehow met during the first years of implementation; the demand for ICT courses and services were high and exclusive to the telecentre.

With the appearance of mobile technologies in the country, community needs shifted, with mobile phones becoming affordable and socially sustainable compared to telecentres, the mobile industry growth casted shadow on the two existing telecentres [6].

Sustainability of telecentres remained a key challenge, addressed in the year 2000 by a scale-up project funded by UNESCO: the scale-up project consisted in increasing the technological infrastructure in the telecentre, and in merging it with the community radio operating on the same venue $[7,8]$. That was the very beginning of CMC: Community Multimedia Centers.

A research and development project called RE-ACT (social Representations of community multimedia centers and ACTions for Improvement), run in 2011-2014 by the Università della Svizzera italiana (Lugano, Switzerland) and by the University Eduardo Mondlane (Maputo, Mozambique), performed in 2011 field trips throughout all provinces of Mozambique to collect data about communities' perception and adoption of CMCs.

CMCs in Mozambique face three common problems: financial sustainability, inability to meet local needs, inability to get technical assistance [2, 9-11].

These problems arise when the income generated doesn't cover operating costs; or other venues do exist close to it providing similar services at a lower cost. In some cases communities are not aware of the services offered by the CMC, or the services are just offered for free.

CMCs are located in rural areas, where to repair, purchase or perform (preventive) maintenance on equipment is financially not feasible.

Community adoption of CMC means how communities perceive it: adoption of $\mathrm{CMC}$ services is lower in locations where local communities perceived the CMC as being just a technology provider, adoption is higher in locations where the CMC is perceived as a space for social and cultural exchanges. 


\section{Morrumbene}

The Morrumbene district is located in the center of the Inhambane province, approximately $450 \mathrm{~km}$ north of Maputo, the capital of Mozambique. It has a largely dispersed population of 110,817 inhabitants, and a land extension of 2,608 $\mathrm{km}^{2}$ [12]. The district is known for its wonderful beaches, tranquility, vibrant culture, and resorts built with a mixture of western and local architecture.

District's main economic activities are fishing, tourism, and agriculture. Fishing and agriculture activities are for subsistence (artisanal), while tourism has contributed to develop rural areas, and to rise demand on local agriculture and fishing industry [13].

The Ministry of Science and Technology (MCT) founded the Morrumbene CMC in 2010, and its management has been entrusted to a local association, named Associaçao Juvenil a Chama.

The CMC offers basic computer training (word, excel, power point, access, and internet). The Community Radio transmits in Portuguese and Xichangana, and covers the entire Morrumbene district plus the neighboring districts of Maxixe and Homoine. Additionally, information and communication services like newspapers, seminars, and cinema on weekends are also provided [14].

The CMC has 14 volunteers, mostly local teachers pursuing a degree in education and students of $10^{\text {th }}$ and $12^{\text {th }}$ grades, all members of the local association.

The communication infrastructure in the district has several limitations; the telephone line doesn't reach the location where the CMC is established: they rely on mobile phones to acquire information. The Internet broadband is accessed by using a very small terminal (VSAT), with free access up to 6 GB per month financed by the MCT. Other Internet providers such as mobile companies are also available, but more expensive.

\section{Methodological Framework}

The methodological framework used in this action-research is co-design, following a similar path of participatory design, although it's seen as an evolutionary approach to technology design for socio-economic development.

The methodology is associated with two approaches: inclusion and empowerment, characteristics that gained increased attention in the more mature years of Information and communication technologies for development (ICT4D) research and practice [15].

Co-design refers to the conception or creation of artifacts drawing on a shared vision, social learning and mutual understanding among all key stakeholders, taking into account that all those involved in the design process have somehow different perspectives and expectations, which should be adequately considered [16]. Literature on community design outlines stakeholders, context, ownership, social learning, and sustainability as problem domains to be addressed during socio-technical experiments $[16,17]$.

To ensure ownership and empowerment, and to provide optimal learning conditions, the implementation followed in every phase three codes of conduct: 
1. Communities views and concerns regarding technology had to be taken into consideration;

2. Every participant, regardless of their educational background, social status, was considered an expert on their own domain;

3. The main sources of design ideas and innovations are from within the community;

The co-design process used at the Morrumbene district was a participatory assembly for inclusion and sharing of ideas, only accepted when consensus about a topic was reached [18].

The process followed two distinct phases:

- Focus group sessions; and

- Website design.

\subsection{Focus Group Sessions}

The RE-ACT project aimed at creating an "improvement action" for the Morrumbene $\mathrm{CMC}$, the goal was to co-design a technological solution with inherent value for the community.

The process to select and implement the improvement action had two distinct focus group sessions, the first session held at the University Eduardo Mondlane (UEM) in Maputo, and the second one at the Morrumbene CMC in the Morrumbene district.

The improvement actions were small-budget projects co-designed such that implementation was to be performed by the CMC overseen by the community, and RE-ACT team. The improvement action envisioned to be implemented by the Morrumbene CMC was a tourism website, idea conceived during the first co-design session held at UEM.

This first co-design session had as participants' nine CMCs directors, as well as representatives of MCT, UNESCO, and UEM entities that performed the establishment and scale-up project of CMCs in Mozambique.

The second stage of the focus group had three sessions held at the Morrumbene district.

The first focus group session held in Morrumbene was devised to build a good relationship between co-design session intervenient, and to acquire knowledge capabilities, area of expertise, contribution, and limitations of participants.

In order not to limit, but to manage expectations and enable participants to voice their views, all sessions in Morrumbene where led by the CMC director, who started presenting the concept of improvement actions, consisting in the tourism website. The local community rejected the idea, voicing concerns about inclusion, and declaring that tourism entrepreneurs and authorities have their websites in English, designed, hosted, and maintained elsewhere.

With unviable conditions to produce a website, a question was raised by the CMC.

"What should we implement that will allow inclusion of all social groups in the district?"

Through the second session discussions, consensus was reached to invite actors with relevant information and knowledge about community core activities; participants comprised then members of police, health service, fisherman association, local entrepreneurs, resort owners, teachers, local youth and religion leaders. 
The second session produced a fruitful discussion around the services that have inherent value for district social groups, unanimity was reached to design a website about the Morrumbene district with the aim to connect people from the district living in and outside. The website had to contain information about the education sector, police information (safety and local reports), health information, and information about commerce.

As the website would only connect people from the community with knowledge and access to computers or smartphones, to mitigate this exclusion it was decided to share information on the website using Short Messaging Service (SMS). These messages were to be sent only to people who subscribed to specific website categories; exception was placed on urgent police and health information, which is sent to all registered numbers.

\subsection{Website Design}

The website design was carried by the CMC, overseen by the community and the REACT team.

The CMC was responsible for defining the website template using joomla; it was also responsible to collect information from the community and to host on the website.

Training and selection of open source technologies for the website and SMS platform was the responsibility of the RE-ACT team. The solution selected for the SMS platform was PlaySMS, compatible with Hypertext Preprocessor (PHP); the RE-ACT team and MCT provided training on those technologies.

The community was responsible for testing de solutions, and evaluates the overall project.

The CMC and RE-ACT team performed the assessment and evaluation, the community was informed about the progresses of the project once a month, through a radio program. The website and the SMS were verified and analyzed using observium network management, and Google analytics.

\section{Result}

This section will focus on the relevant results related to:

(1) Community participation;

(2) Empowerment;

(3) Ownership; and

(4) Sustainability.

The co-design process resulted in a community website (www.cmcmorrumbene. co.mz), consisting of information about the $\mathrm{CMC}$, community radio, government, police, school results (primary, secondary), local publicity, public opinion quiz, and a webmail.

To include higher number of people in the community, an SMS solution was designed to provide quick information to the community about the local market price (fish, vegetable), health tips, and security-related issues. 
The CMC staff was trained in web-design and progressively introduced new features in the website. Such training brought to CMC staff independence, and confidence when it comes to using web design and development tools.

The CMC staff became active and decisive on local practices and use of technologies for social inclusion [19].

As the number of people registered for the SMS service, reached 134 in the first month, to sustain the SMS service the community emphasized the need of selling some of CMC services in exchange for SMS balance or mobile balance transference. The actual number of subscribers for the SMS service is 686 , for each community member or house only one number is registered.

As communities best know their life context and therefore are entitled to contribute with finding solutions for local problems [20], the community proposed that services such as cinema tickets, radio announcements and music selection should be charged based on SMS recharge or mobile balance transference. To use alternative types of currency might seem unusual to some people [21, 22], literature on forms of money suggests that what works best is to have a currency that fits a specific purpose or mean for payment of a specific service [23].

\section{Conclusion}

Community's focus groups sessions undoubtedly provided liberty of expression to participants; the RE-ACT team followed the approach of assembly gathering during the session, as this is a community local and traditional costume. This created conditions for cohesion, and strengthen relations between researcher and community.

Although when working with communities goals are framed and reframed several times, every co-design session produced consensus, and mutual understanding among intervenient. Commitment was observed by how intervenient devoted time, knowledge, attention and patience to design and draft the final solution. Dialog at all social levels to find shared solutions for domain problems is an exploration of spaces to invite possibilities to share past experiences and contextual knowledge.

Ownership of the designed solution was attained thanks to the involvement of all core businesses in the district. It was also achieved by providing freedom to change, veto, and reformulate the final solution.

The inclusive framework on the website design was equality and respect, so to make it visible the collaboration of individuals with social and political differences.

\section{References}

1. Oyedemi., T.D.: Social inequalities and the South African ICT access policy agendas. Int. J. Commun. 3, 11-18 (2009)

2. Kuriyan, R., Kitner, K., Watkins, J., Gomez, R., Gould, E.: The 'cool factor' of public access to ICT: Users' perceptions of trust in libraries, telecentres and cybercafés in developing countries. Inf. Technol. People 23(3), 247-264 (2010) 
3. Sey, A., Coward, C., Bar, F., Sciadas, G., Rothschild, C., Koepke, L.: Connecting People for Development: Why Public Access ICTs matter (eBook). Technology \& Social Change Group, Seattle (2013)

4. W. H. Organization: World health statistics 2010. World Health Organization (2010)

5. Gaster, P.: A pilot telecentres project in Mozambique. In: Latchem, C., Walker, D. (eds.) Telecentres: Case studies and key Issues, pp. 119-121. The Commonwealth of Learning, Vancouver (2001)

6. Sey, A., Fellows, M.: Literature review on the impact of public access to information and communication technologies, Center for Information \& Society, University of Washington, Seattle (2009)

7. Vannini, S., Rega, I.: Inbound and outbound information and communication flows: perspectives from community multimedia centres in Mozambique. In: CIRN 2012 Community Informatics Conference: 'Ideals Meet Reality', Monash Centre. Presented at the CIRN (2012)

8. Naidoo, M.: The changing venues for learning. Doc. RESUME, 18 (2001)

9. Van Zyl, I., Vannini, S.: Participatory Re-action: Reflecting on a Design-Based Research Approach in ICT4D (2013)

10. Baia, A., Macueve, G., Rega, I., Cumbula, S.D., Vannini, S., Cantoni, L.: Social Representations of Multimedia Community Centers (CMC) in Mozambique. Electron. J. Inf. Syst. Develop. Countries 65(8), 1-23 (2015)

11. David, S., Vannini, S., Sabiescu, A.G., Cantoni, L.: Commitment, proactivity and trust: ingredients for successful cooperation in community development actions. In: Proceedings of the CIRN 2013 (2013)

12. Kampango, A., Cuamba, N., Charlwood, J.D.: Does moonlight influence the biting behaviour of Anopheles funestus? Med. Vet. Entomol. 25(3), 240-246 (2011)

13. Cardinale, M., Chacate, O., Casini, M., Chaúca, I., Helge Vølstad, J.: CPUE trends of Hilsa kelee and Thryssa vitrirostris exploited by the artisanal finfish fisheries in Mozambique derived from an on-shore sampling of catches by trip. Sci. Mar. 78(1), 55-64 (2014)

14. Rega, I., Cantoni, L., Vannini, S., David, S., Baia, A., Macueve, G.: Community Multimedia Centres in Mozambique: a Map. White Paper (2011)

15. Avgerou, C.: Information systems in developing countries: a critical research review. J. Inf. Technol. 23(3), 133-146 (2008)

16. David, S., Sabiescu, A.G., Lorenzo, C.: Co-design with Communities. a reflection on the literature. In: Steyn, J., Van Vyver A.G. (eds.) 2013 Public and Private Access to ICTs in Developing Regions, Proceedings of the 7th International Development Informatics Association Conference, pp. 152-166, Bangkok, Thailand (2014). ISBN 978-0-620-58040-3

17. Camara, S.B., Noø era, J.A., Dunckley, L.: Exploring the problem domain: a socio-technical ICT design for the developing world. In: Proceedings of the Tenth Anniversary Conference on Participatory Design 2008, pp. 154-157 (2008)

18. Winschiers-Theophilus, H., Winschiers-Goagoses, N., Rodil, K., Blake, E., Zaman, T., Kapuire, G.K., Kamukuenjandje, R.: Moving away from Erindi-roukambe: transferability of a rural community-based co-design. In: IFIIP WG, vol. 9 (2013)

19. Warschauer, M.: Technology and Social Inclusion: Rethinking the Digital Divide. MIT press, Cambridge (2004)

20. Weinberg, T.: The new community rules: Marketing on the social web. O'Reilly Media, Inc., Sebastopol (2009) 
21. Krugman, P.: Competitiveness: a dangerous obsession. Foreign Aff. 73(2), 28-44 (1994)

22. Davenport, T.H., Beck, J.C.: The Attention Economy: Understanding the New Currency of Business. Harvard Business Press, Cambridge (2013)

23. Boyle, D.: More than Money: Platforms for Exchange and Reciprocity in Public Services. NESTA, London (2011) 